\title{
DEVELOPMENT OF SMART PRECISION FOREST IN CONIFER PLANTATION IN JAPAN USING LASER SCANNING DATA
}

\author{
M. Katoh ${ }^{\mathrm{a}, *}$, S. Deng ${ }^{\mathrm{a},}$, Y.Takenaka ${ }^{\mathrm{a}}$, K. Cheung ${ }^{\mathrm{a}}$, K. Oono ${ }^{\mathrm{b}}$, M. Horisawa ${ }^{\mathrm{c}}$, J. Hyyppä ${ }^{\mathrm{d}}$, X.Yu ${ }^{\mathrm{d}}$, X. Liang ${ }^{\mathrm{d}}$, Y. Wang ${ }^{\mathrm{d}}$ \\ ${ }^{a}$ Institute of Mountain Science, Shinshu University, 8304, Minamiminowa-Vill. Kamiina-County, Nagano, 399-4598, Japan, \\ (mkatoh, deng, 16as406j,17as409g)@ shinshu-u.ac.jp \\ b Asia Air Survey Co. Ltd, 1-2-2 Manpukuji, Kawasaki, Kanagawa, 215-0004, Japan, kat.oono@ajiko.co.jp \\ ' Kita-Shinshu forest owners' cooperative, 938-1 Kabeta, Nakano, Nagano, 399-4598, Japan, m.horisawa@jforest-kitashinshu \\ ${ }^{\mathrm{d}}$ Finnish Geodetic Institute, Geodeetinrinne 2, PL 15, 02431 Masala, Finland,(juha.hyyppa, xiaowei.yu, xinlian.liang, \\ yunsheng.wang@nls.fi)
}

Commission III, WG III/4

KEY WORDS: Laser scanning, precision forestry, 3D technology, LIDAR, UAV, Mobile, National practice project, Japan

\begin{abstract}
Currently, the authors are planning to launch a consortium effort toward Japan's first smart precision forestry project using laser data and to develop this technology throughout the country. Smart precision forestry information gathered using the "Nagano model" (laser scanning from aircraft, drone, and backpack) is being developed to improve the sophistication of forest information, reduce labor-intensive work, maintain sustainable timber productivity, and facilitate supply chain management by laser sensing information in collaboration with industry, academia, and government. In this paper, we outline the research project and the technical development situation of unmanned aerial vehicle laser scanning.
\end{abstract}

\section{INTRODUCTION}

\subsection{Forestry in Japan}

Forests occupy approximately two-thirds (about 25 million ha) of the land area in Japan. About 10 million ha of this forest area is coniferous plantation forests, and about $51 \%$ of this coniferous forest produces timber 50 or more years of age. Cutting and using this forest resource is important to the country's forestry industries.

However, there are several problems pertaining to the forest in Japan. (1) Current forest resources are measured manually, steep mountain topography is common, Sasa bamboo groves grow within the forests, and there are many types of dangers. Hence, the accuracy of the information obtained is low relative to the excessive cost of surveying. Additionally, expenditures for forest management and administration are decreasing, and the reliability of forest information is declining. (2) Individual owners have no assurance of long-term income from timber, so they are often indifferent to the forest. Hence, boundaries are unclear, and the extent of forest that has not been tended is increasing. (3) Furthermore, domestic forest resources often are not utilized, with wood imports filling $70 \%$ of the demand for forest products.

(4) As a remote sensing methodology, laser scanning (LS) has attracted attention as a technology that can produce highly accurate 3D information, and it has been adopted by ministries, prefectures, and cities across Japan. However, because of limitations on the use of LS data and the expense of acquiring such data, the area-based approach (ABA) and individual tree detection (ITD) technologies have not been put to practical use (Næsset, et al., 2002), (Hyyppä, et al., 1999), (White, et al. 2013). Compared to the advanced LS technology used in northern Europe, Japan is 3 years behind (Nasset, et al., 2004), (Yu, et al., 2010), (Vastaranta, et al., 2012), (Hyyppä, et al., 2012), (Kaartinen, et al., 2012), (Wang, et al., 2016).

\subsection{LS technology in Japan}

(1) Although low-density airborne laser scanning (ALS) with a point density of 1 point $/ \mathrm{m}^{2}$ was undertaken for each watershed in Japan, the institution implementing the scanning was the Ministry of Land, Infrastructure and Transport's River Improvement Department, and the data gathered were not disclosed. Information was not even received at educational institutions such as universities, where ALS data are required. This problem has been improved in recent years, as a portal site for nationwide ALS data has been established, and open data use has begun.

(2) Because the low-density ALS data were not disclosed, no ABA, which is an effective approach for efficiently understanding forest resources, has been placed into practical use.

(3) Although the Forestry Agency of the Ministry of Agriculture (FA), Forestry and Fisheries, manages the forest, information sharing of low-density ALS data was not done well.

FA is promoting high-density ALS with a point density of four or more points per square meter, but it has only covered $20 \%$ of the forest area due to high-LS data-acquisition expenses. Fortunately, Nagano Prefecture, where our university is located, has taken over the responsibility for the entire privately owned forest using a high density of five points per square meter.

(4) National forests, which account for about $30 \%$ of forests in Japan, have not been measured by ALS, and practical LS use has not been put in place.

(5) Terrestrial laser scanning (TLS), drone LS, and mobile LS systems have been initiated experimentally in various places, but these have not been organized or systematized.

* Corresponding author 


\section{SMART PRECISION FORESTRY PROJECT IN JAPAN USING LASER SCANNING}

To resolve the issues mentioned above, the authors have developed integrated information technology for obtaining useful forest information, including ALS, drone LS, personal LS (PLS) carried by backpack, and TLS, which saves manual labor for forest monitoring and enables sustainable timber productivity. We developed the "Nagano model" of smart precision forestry, which has improved timber supply chain management by industry and academia and facilitated government collaboration. This section outlines the research project and introduces the technical development status of drone LS within the project.

\subsection{Project details}

The contents of the project are shown in Fig. 1. We will prepare 3D precision ITD information using LS data from ALS, drone LS, and PLS. Next, we will select harvest trees with the program using the $3 \mathrm{D}$ precision database. We will use the high-performance harvester (MaxiXplorer) with Internet of Things (IoT) functionality locally to produce logging, branch cutting, and timber cutting. The timber supply chain can be built by linking single-tree information from the harvester operator to offices and sawmill companies via the Internet.

This research is a large-scale project related to the innovative technology development initiative of the Ministry of Agriculture, Forestry and Fisheries for 2016-2020. The research budget is EUR 0.8 million.

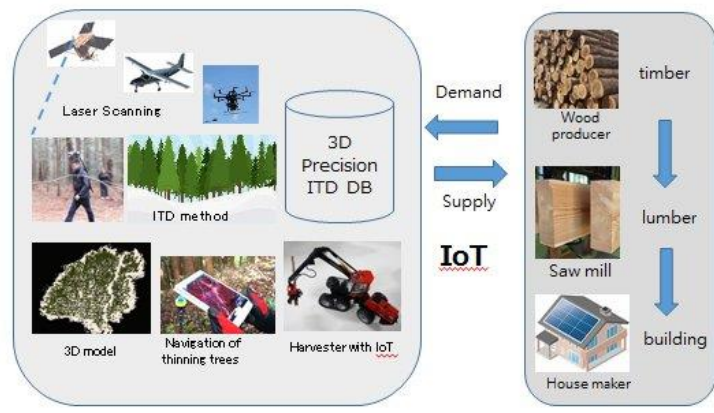

Smart precision Forestry and Supply management chain by loT (Quality, Cost, Delivery)

Figure 1. Smart precision forestry project in Japan

\subsection{Framework of Smart Precision Forestry Consortium}

Participating organizations are Shinshu University, KitaShinshu forest owners' cooperative, Air Survey Co. Ltd, KOMATSU(cooperating organizations), Nagano Prefecture, Nagano Prefecture Forestry Association Federation, Chubu district Forestry Administration Bureau of National forest (cooperation). Shinshu University is a consortium's comprehensive body in cooperation with the national government, local governments, forestry enterprises and private enterprises, and the author is the project leader.

\subsection{Shinshu University's Approach}

Shinshu University is working on an accurate forest resource survey using drone LS and a ground-based harvest survey using PLS. We conducted empirical research at the North Shinshu
Forestry Association of Private Forest and the Chushin Forest Management Office of National Forest. We developed precision resource calculation technology for single-tree information, including $\mathrm{X}$ and $\mathrm{Y}$ coordinates, crown diameter, height, diameter at breast height $(\mathrm{DBH})$, volume, and other data.

Our drone laser is used in combination with M940 Japanese domestic drones made by enRouteM's and the Surveyor laser sensor produced by YellowScan.

We first perform scanning before thinning the conifer plantations, and then extract precise single-tree resources by the ITD method. Next, we re-survey the harvested forest after logging at the site. We overlay the two different time-period LS images and automatically extract and verify the thinned trees.

When using aircraft or drones, there is a limit to the amount of information that can be obtained beneath the forest canopy. Therefore, we are developing a backpack PLS system that can be used while walking that accurately measures the forest from the ground level in 3D in collaboration with the Finnish Geodetic Institute (FGI). Using the backpack laser, we can measure the shape of the upper trunk stem, any bending affecting timber values, and so forth, as well as the situation of the middle and lower tree.

\section{ACCURATE FOREST RESOURCE SURVEY WITH DRONE LASER SCANNING}

The objective of this work is to obtain accurate forest information by the ITD method safely and in a short amount of time by using advanced drone LS for the logging target area (5-20 ha). The current forest resource survey method uses a sample survey based on standard sites, and human error may affect the survey's accuracy. Most of the forests in Japan are in steep mountainous terrain, the middle and lower-level vegetation is lush, and the forest floor includes tall bamboo grass and high-density areas. This method of investigating forests is inefficient, and it requires additional expense, as these locations have poor vantage points and footholds. Currently, the demand for timber production in Japan is increasing the requirement for forest surveying for harvesting, and securing the necessary number of investigators is an issue.

\subsection{Study area}

The research sites were Shiojiri City, Nagano Prefecture, and the national forest in the Nara District. The tree species was Japanese larch, 63 years old, and the logging method was 50\% band clear-cutting at 20-m intervals. The red area showed harvested area was 2.37 ha of 4.44 ha (Fig. 2).

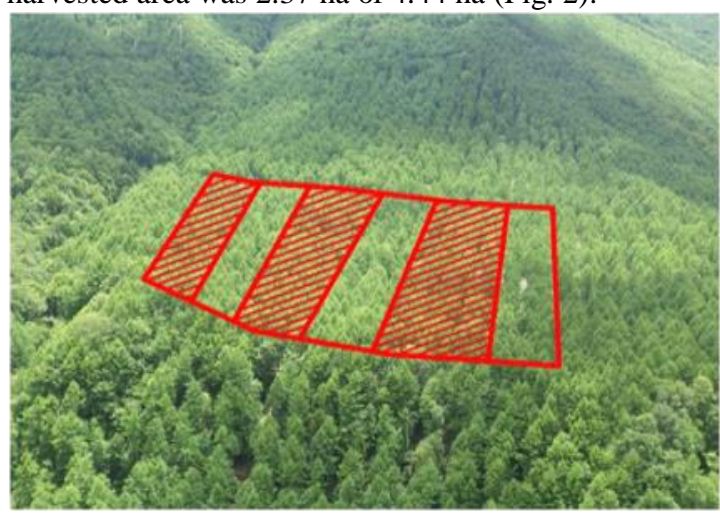

Figure 2. Study area 


\subsection{UAV-LS}

The unmanned aerial vehicle (UAV) used was an enRouteM's M940 industrial drone, which was a hexacopter with six propellers, suitable for aerial shooting with cameras and sensors; the distance between the motor diagonal axis is 940 $\mathrm{mm}$. The laser used was the YellowScan (France) Surveyor, which is suitable for precise topography determination and forest monitoring (Fig. 3). Scanning and photography were done by Ace-1, Ltd., and data pre-processing was done by Mirukuru, Ltd. in Tokyo.

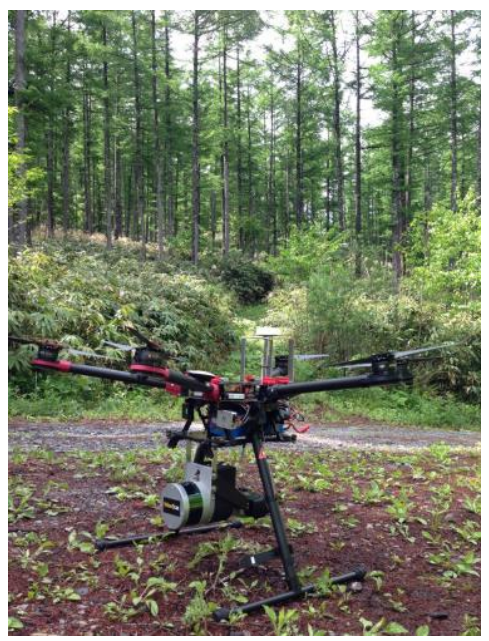

Figure 3. UAV-LS

Laser scanning was conducted twice, on August 24, 2016, before thinning, and on November 15, 2016, after thinning. The first shot was from an altitude of $100 \mathrm{~m}$, and then a shot was taken at an altitude of $50 \mathrm{~m}$ from the forest crown. The point clouds had a density of 50 points per square meter, and the trajectory of flight was set to $80 \%$ overlap.

\subsection{Image interpretation of canopy height model}

From the drone LS data, a digital surface model (DSM), digital terrain model (DTM), and digital canopy height models (DCHM) were created with ground pixel resolution of $5 \mathrm{~cm}$. Details of branches could be obtained for each single tree from the DCHM images, as shown in Fig. 4. We found that DSM and DCHM by drone LS were superior for image interpretation compared with ALS, and they were suitable for analysis at the single-tree level, such as for thinning and harvesting.

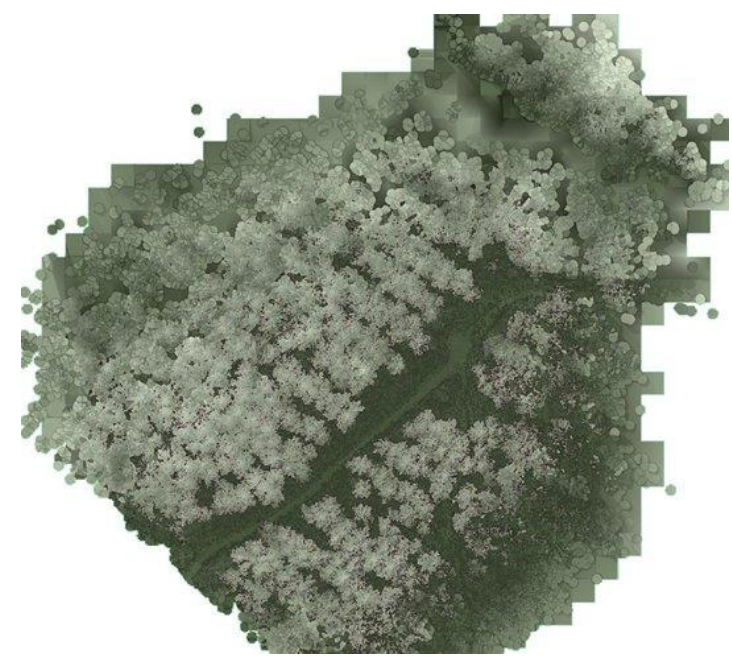

Figure 4. Image interpretation of an enchanted CHM

3.4 Precise crown extraction by individual tree detection method

The original LS data were influenced by abnormal values caused by hardware and noise caused by sensors, which resulted from overlapping forest crowns, long branches, and underlying vegetation. To automatically extract the precise crown by the ITD method, it was necessary to eliminate such noise and preprocess by filtering and statistical means to clarify the outline of the forest canopy. Figure 5 shows the usefulness of the ITD method after eliminating data noise and removing forest roads and underlying vegetation. Tree height was extracted by assigning the maximum DCHM to one crown.

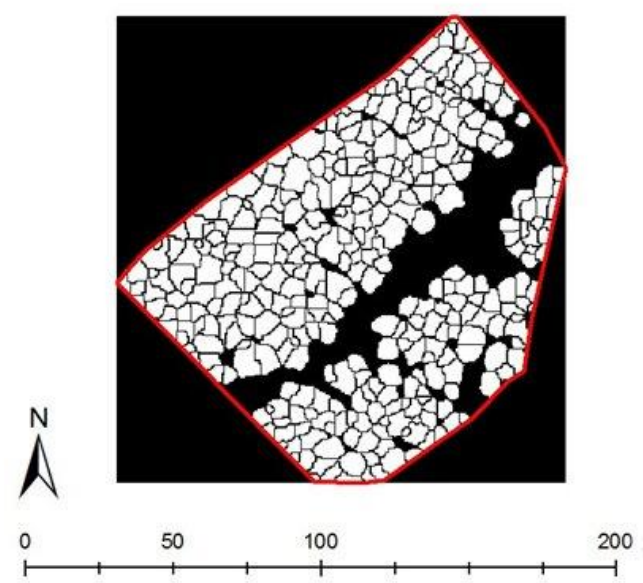

Figure 5. Precise crown extraction by ITD method

\subsection{Calculation of tree attribute information}

Individual tree information, including tree number, position $(\mathrm{X}, \mathrm{Y})$, crown diameter, and crown area was calculated automatically in Table-1 :

Tree height was taken as the point group of maximum CHM value within the crown.

Diameter at breast height was estimated from multivariate analysis for every crown diameter and tree height. 
Volume was automatically calculated from DBH, tree height, and tree volume with conifer species from tree volume formula.

The analysis result was made available using MS Excel for easy use by members of the Smart Precision Forestry Consortium.

Table-1. Calculation of tree attribute information

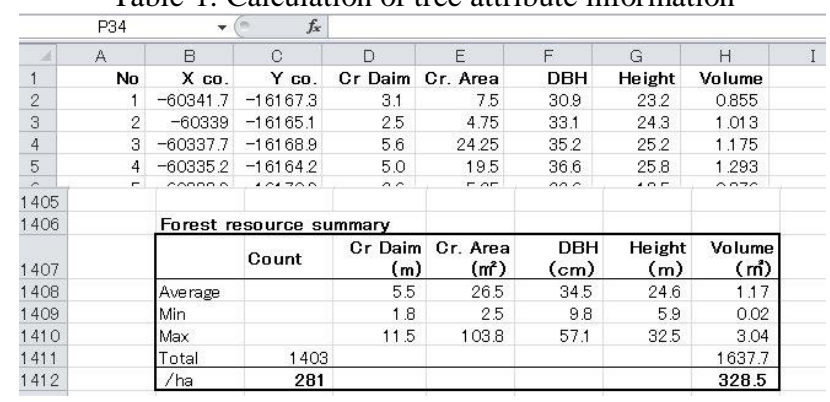

\subsection{Accuracy verification}

Before harvesting, a plot area $(30 \times 70 \mathrm{~m})$ investigation of every tree was carried out in the field. The results of these tree investigations were then compared with the tree information analyzed by drone LS.

The single-tree survey included all trees with diameter at breast height $(\mathrm{DBH})$ greater than $8 \mathrm{~cm}$.

The survey items were tree position ( $\mathrm{X}, \mathrm{Y}$ coordinates), tree species, target conifer species or hardwood, $\mathrm{DBH}$, and tree height. The tree heights were actually measured by measuring survey when trees were felled.

For accuracy verification, we employed a precise crown and tree top position (red) developed by drone LS and a standing tree position (green) measured by the field survey in Fig.6, and thereby confirmed the identified and unidentified trees within a plot of $70 \times 30 \mathrm{~m}$ using two-person teams.

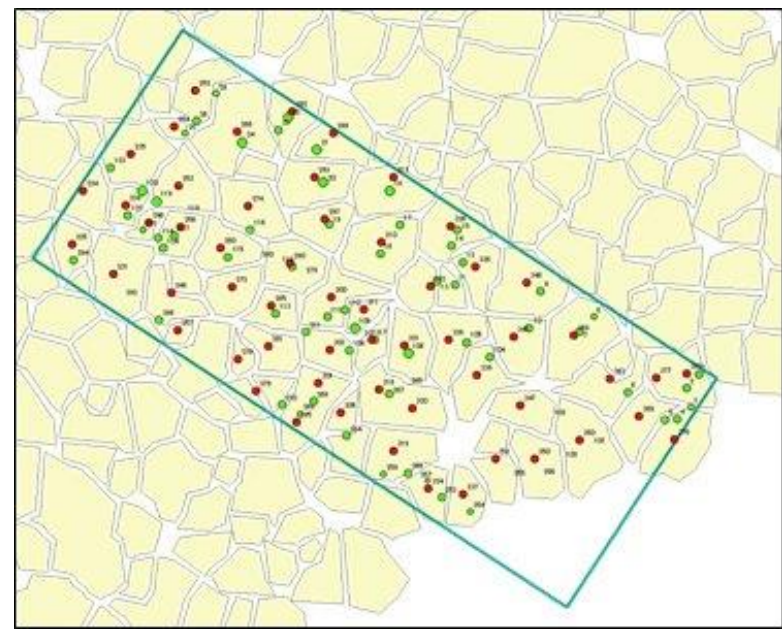

Figure 6. Accuracy verification

The accuracy of each tree investigation was compared with the tree information analyzed by Drone LS.

The accuracy verification result is shown in Table-2. The number of standing trees recorded by the single-tree investigation (DBH of $8 \mathrm{~cm}$ or more) was 70 , and the number of standing trees detected by drone LS was 57; thus, the singletree detection rate was $81 \%$. The 13 trees undetected by drone LS were mid-level trees within overcrowded populations and trees difficult to image from the sky.

Table-2 Accuracy verification

\begin{tabular}{|l|r|r|r|r|r|}
\hline & $\begin{array}{c}\text { Field } \\
\text { Survey }\end{array}$ & $\begin{array}{c}\text { Drone- } \\
\text { LS }\end{array}$ & $\begin{array}{l}\text { Drone's } \\
\text { undetected } \\
\text { tree }\end{array}$ & $\begin{array}{c}\text { Drone's } \\
\text { detection } \\
\text { rate( }(\%)\end{array}$ \\
\hline Count & total & 70 & 57 & 13 & $\mathbf{8 1 . 0}$ \\
\hline $\begin{array}{l}\text { Volume } \\
(\text { m } / \text { ha })\end{array}$ & total & 392 & 350 & 42 & $\mathbf{8 9 . 0}$ \\
\hline
\end{tabular}

\begin{tabular}{|c|c|c|c|c|}
\hline & & $\begin{array}{c}\text { Field } \\
\text { Survey }\end{array}$ & $\begin{array}{l}\text { Drone- } \\
\text { LS }\end{array}$ & $\begin{array}{c}\text { Error } \\
\text { between } \\
\text { both }\end{array}$ \\
\hline \multirow{3}{*}{$\begin{array}{c}\mathrm{DBH} \\
(\mathrm{cm})\end{array}$} & Average & 33.4 & 33.6 & -0.4 \\
\hline & Min & 10.2 & 25.5 & \\
\hline & Max & 54.5 & 45.0 & \\
\hline \multirow{3}{*}{$\begin{array}{c}\text { Height } \\
(\mathrm{m})\end{array}$} & Average & 25.5 & 25.5 & -0.004 \\
\hline & Min & 16.1 & 20.0 & \\
\hline & Max & 30.4 & 31.6 & \\
\hline \multirow{3}{*}{$\begin{array}{c}\text { Volume } \\
(\mathrm{rn})\end{array}$} & Average & 1.2 & 1.1 & 0.1 \\
\hline & Min & 0.1 & 0.5 & \\
\hline & Max & 2.7 & 2.3 & \\
\hline
\end{tabular}

Finally, we created 3D model of Drone-LS visualizing changes before and after thinning in Fig.7 .

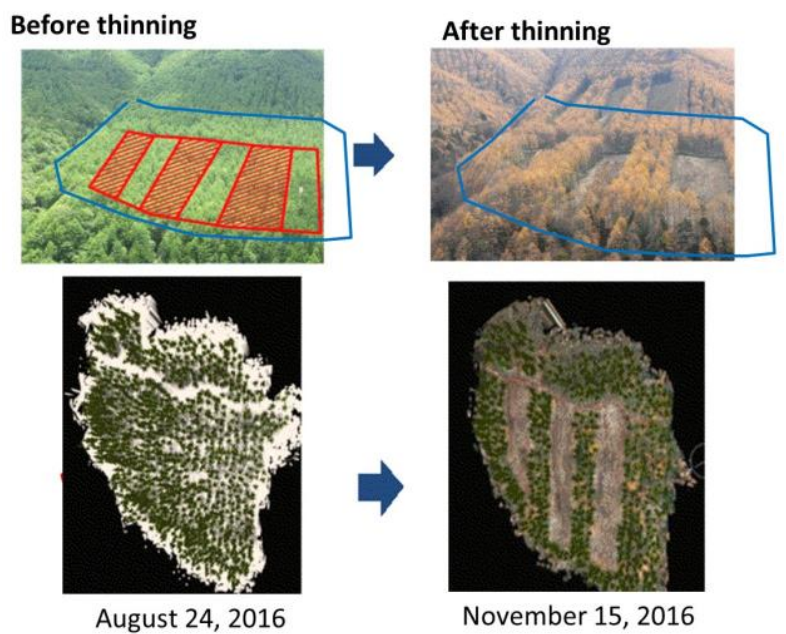

Figure 7 3D model of Drone-LS visualizing changes before and after thinning.

\subsection{Efforts in 2017}

1) We are developing a tree-thinning selection program based on drone LS single-tree information. The position information of trees to be harvested is transmitted to the chainsaw operator working with the logging assistant and maxiXplorer operator, who navigate and cut the trees. The harvested timber information is uploaded to the Internet for management in a cloud database to facilitate wood sales to sawmill companies. 2) PLS is being co-developed with the FGI for measurement in various forests where tree species, forest age, and thinning rate vary (Jaakkola, et al., 2012), (Liang, et al., 2014). We will work on an analysis of 3D detailed information on individual trees and consider its use for a harvesting survey of wood value categories (A, B, and C rankings). 
3) We are applying the developed ITD method by drone LS to DSMs derived from UAV (DJI Co., Phantom 4 Pro) by the structure from motion (SfM) method and DEMs derived from ALS.

4) Field confirmation of high-accuracy position information of trees for harvesting will be improved greatly by the Japanese satellite positioning system Michibiki No. 3, launched on August 19, and No. 4, to be launched during the current fiscal year. Additionally, in the spring of 2018, four satellites (three over Japan and one above the equator) will begin operation. At least one of the four will always be over Japan, and the highly accurate location information service will be available to us at any time. It is expected that the position accuracy of $10 \mathrm{~m}$ will be improved to $6 \mathrm{~cm}$.

5) The Advanced Land Observation Satellite (ALOS) No. 3 optical high-resolution satellite will be launched at the end of 2019. It has a wide observation range $(70 \mathrm{~km})$, high spatial resolution $(80 \mathrm{~cm})$, and RedEdge band addition, and it is expected to be available for forest vegetation analysis. A widearea 3D image will be obtainable at low cost, and it will be capable of use with ALS for improved tree species classification, forest information updates, and forest attribute data improvement.

6) We will use the open low-density ALS to begin a demonstration test of a forest resource investigation using the ABA method in the national forest. If the operation cost of high-density ALS is as low as that in Scandinavian countries, ITD can be developed for precision forestry in private forest areas as well. Our goal is to practice in Japan the ALS precision forestry used in Scandinavia (Holopainen,, et al., 2014),

7) As a venture of Shinshu University, we established the Precision Forestry Measurement Co., Ltd., to develop the business of 3D technology and forestry innovation in Japan.

\section{CONCLUSION}

1. Japan's smart precision forestry with LS aims to grow forestry industries, as Japan's forests are being harvested. 2. Our project will undertake active model development in Nagano Prefecture, focusing on forestry production and obtaining a large-scale research budget. The project will eventually spread nationwide.

3. Shinshu University is the consortium's comprehensive body, working in cooperation with the national government, local governments, forestry enterprises, and private enterprises. Professor Katoh is the project leader.

4. Shinshu University works toward accurate forest resource surveying with drone LS and ground-based harvest surveying using PLS.

5. We developed precise individual tree crown extraction and attribute information extraction for each single tree from highdensity point cloud $\left(50\right.$ points $\left./ \mathrm{m}^{2}\right)$ drone LS data.

6. Results of the comparison of drone LS data with the field survey data showed that the extraction rate of the number of standing trees detected by drone LS was about $80 \%$, and the volume extraction rate was $90 \%$. Undetected trees were beneath tree crowns and were low-level trees within a highdensity group.

\section{ACKNOWLEDGEMENT}

This research has been co-financed by the innovative project: Development of sustainable smart precision forestry using laser scanning technology from the National Agriculture and Food Research Organization (Grant Number 16822347) and a Grantin-Aid for Scientific Research from the Japan Society for the Promotion of Science (JSPS KAKENHI Grant Number JP17H03827).

\section{REFERENCES}

Næsset, E. 2002, Predicting forest stand characteristics with airborne scanning laser using a practical two-stage procedure and field data. Remote Sens. Environ. 80, pp. 88-99.

Hyyppä, J., Inkinen, M., 1999 Detecting and estimating attributes for single trees using laser scanner. The Photogrammetric Journal of Finland, 16(2), pp.27- 42

White, J.C.; Wulder, M.A.; Varhola, A.; Vastaranta, M.; Coops, N.C.; Cook, B.D.; Pitt, D.; Woods,2013. A best practices guide for generating forest inventory attributes from airborne laser scanning data using an area-based approach. Natural Resources Canada, Canadian Forest Service, Canadian Wood Fibre Centre, Victoria, BC. 50p

Næsset, E, Gobakken, T, Holmgren, J, Hyyppä, H, Hyyppä, J, Maltamo, M, Nilsson, M, Olsson, H, Persson, Å, Söderman, U. 2004, Laser scanning of forest resources: The Nordic experience. Scand. J. For. Res. 19, pp. 482-499.

Yu, X, Hyyppä, J., Holopainen, M. \& Vastaranta, M. 2010. Comparison of area based and individual tree based methods for predicting plot level attributes. Remote Sensing, 2, pp. 1481-1495.

Vastaranta, M., Kankare, V., Holopainen, M., Yu, X., Hyyppä, J. \& Hyyppä, H. 2012. Combination of individual tree detection and area-based approach in imputation of forest variables using airborne laser data. ISPRS Journal of Photogrammetry and Remote Sensing 67, pp. 73-79.

Hyyppä, J, Yu, X, Hyyppä, H, Vastaranta, M, Holopainen, M, Kukko, A, Kaartinen, H, Jaakkola, A, Vaaja, M, Koskinen, J. \& Alho, P. 2012. Advances in forest inventory using airborne laser scanning. Remote Sensing 4,pp. 1190-1207.

Kaartinen, H, Hyyppa, J, Yu, X, Vastaranta, M, Hyyppa, H, Kukko, A, Holopainen, M, Heipke, C, Hirschmugl, M, Morsdorf, F, Naesset, E, Pitkanen, J, Popescu, S, Solberg, S, Wolf, B.M, Wu, J, 2012, An International comparison of Individual tree detection and extraction using airborne laser scanning. Remote Sens. 4, pp. 950-974.

Wang,Y, Hyyppä J, Liang X, Kaartinen H, Yu X, Lindberg E, et al., 2016 International benchmarking of the individual tree detection methods for modeling 3-D canopy structure for silviculture and forest ecology using airborne laser scanning. IEEE Transactions on Geoscience and remote sensing, 54( 9), pp. 5012-5027 
Holopainen, M. \& Vastaranta, M. Hyyppä, J., 2014. Outlook for the next generation's precision forestry in Finland. Forests 5, pp. 1682-1694;

Liang X, Kankare, V, Yu X, Hyyppa, J, Holopainen, M, 2014, Automated stem curve measurement using terrestrial laser scanning. IEEE Trans. Geosci. Remote Sens. 52, pp. 17391748 .

Jaakkola, A, Hyyppä,Y, A Kukko, A, Yu, X, Kaartinen, H, Lehtomäki, M, Lin. Y, 2010 A low-cost multi-sensoral mobile mapping system and its feasibility for tree measurements ISPRS journal of Photogrammetry and Remote Sensing 65 (6), pp. 514-522 